\title{
Bariatric surgery for prospective living kidney donors with obesity?
}

\author{
John R. Montgomery ${ }^{1}$ (D) | Dana A. Telem ${ }^{2}$ | Seth A. Waits ${ }^{1}$
}

${ }^{1}$ Department of Transplant Surgery, University of Michigan, Ann Arbor, Michigan

${ }^{2}$ Department of Minimally Invasive Surgery, University of Michigan, Ann Arbor, Michigan

Correspondence John R. Montgomery

Email:montgomj@med.umich.edu
The obesity epidemic has gripped the transplant community. With nearly $40 \%$ of adults in the United States being obese (BMI $\geq 30 \mathrm{~kg} / \mathrm{m}^{2}$ ) and $20 \%$ being morbidly obese $\left(\mathrm{BMI} \geq 35 \mathrm{~kg} / \mathrm{m}^{2}\right.$ ), the implications for both donors and recipients of solid organs continue to grow. ${ }^{1}$ Nowhere is this more impactful than the candidacy of living kidney donors (LKDs). As increasing numbers of obese adults present for LKD consideration and evidence of inferior outcomes among obese LKDs grows, transplant surgeons will become progressively challenged by how to manage these patients in the clinic. Therefore, we offer this Personal Viewpoint to the transplant surgery community in order to review the current impact of obesity on living kidney donation, highlight what weight-loss interventions have already been attempted, and discuss the role that referral for weight-loss interventions including bariatric surgery might have going forward.

\section{KEYWORDS}

disparities, donors and donation: donor evaluation, donors and donation:living, editorial/ personal viewpoint, kidney transplantation/nephrology, obesity, organ procurement and allocation, organ transplantation in general, patient referral

\section{1 | WHAT IS THE IMPACT OF OBESITY AND METABOLIC SYNDROME ON LIVING KIDNEY DONATION?}

Obesity among adults in the United States has grown from $22.9 \%$ in 1988 to $38.8 \%$ in 2016, with African American and Hispanic populations having disproportionately high rates of obesity $(47.9 \%$ and $44.8 \%$, respectively). ${ }^{1}$ Likewise, morbid obesity has increased from $8.1 \%$ to $17.6 \%$ over the same period. These shifts have directly affected the living kidney donor (LKD) population, with $22.8 \%$ of LKDs being obese and $2.4 \%$ being morbidly obese in 2016 according to United Network for Organ Sharing (UNOS) data. ${ }^{2,3}$ However, these figures only tell part of the story, as they only report patients who have completed donation and fail to capture the magnitude of potential LKDs who have been excluded from donation due to obesity or related metabolic syndromes.
Currently there is no universally accepted BMI cutoff among US transplant centers for potential LKDs, although most centers fall between 30 and $35 \mathrm{~kg} / \mathrm{m}^{2}$. Limited data from single-center studies demonstrate that exclusion rates for obesity vary from $1.8 \%$ to $25 \%{ }^{4-10}$ Similar rates of exclusion apply to hypertension ( $7.6 \%$ to $21 \%$ ), although exclusion due to diabetes is relatively rare (1.2\% to $3.5 \%)$. Exclusion rates due to obesity-related comorbidities may be underestimations, as patients are more likely to be excluded for self-reported obesity during initial phone screening than for undiagnosed comorbidities that are discovered during transplant donor clinic visit.

For those patients with obesity who move forward with donation, single-center studies report inferior postdonation outcomes for both donors and recipients. When compared to normal-weight donors, obese donors are more likely to experience short-term postoperative decline in estimated GFR (eGFR) and have a higher 
long-term risk of developing end-stage renal disease (ESRD) (adjusted hazard ratio [aHR] 1.86, 95\% confidence interval [CI] 1.05-3.30), that is dose-dependent (7\% increase in ESRD risk for each unit increase in BMI above $27 \mathrm{~kg} / \mathrm{m}^{2}$ ) $11-13$ (Table 1). They also have higher postdonation rates of newly diagnosed diabetes (up to $6.3 \%$ ), cardiovascular disease (up to $8.3 \%$ ), hypertension (up to $69 \%$ ), abnormal high-density lipoprotein (up to $44 \%$ ), microalbuminuria (up to $21 \%$ ), and further weight gain (up to $35 \%$ ). ${ }^{14-16}$ These rates are exceptional given that patients with elevated $\mathrm{BMI}$ are often more scrutinized than normal-weight donors for borderline comorbidities. Recipients of kidney from obese LKDs also do worse-they experience a higher risk of graft loss (aHR per $10 \mathrm{~kg} / \mathrm{m}^{2}$ increase in BMI 1.12, 95\% Cl 1.04-1.21), and recipients of kidneys from donors who later develop ESRD have a higher risk of mortality. ${ }^{17,18}$

\section{2 | WHAT INTERVENTIONS HAVE BEEN TRIALED FOR POTENTIAL LKDS WITH OBESITY?}

Given that up to one-fourth of potential LKDs are excluded due to obesity and that those who complete donation have alarmingly high postdonation risks, interventions to encourage weight loss before donation seem obvious. However, published literature on weight-loss interventions for potential LKDs with obesity is sparse, with data on bariatric surgery essentially nonexistent. Only one retrospective, observational study has reported outcomes from a monitored diet program with lifestyle modifications for potential LKDs. ${ }^{5}$ In this study, Sachdeva et al analyzed 23 morbidly obese patients who were excluded from initial living kidney donation due to their weight (BMI $\geq 35 \mathrm{~kg} / \mathrm{m}^{2}$ ). These patients received individualized recommendations for diet and lifestyle modifications by a transplant nutritionist and were followed with monthly phone calls. Even in this group of highly motivated patients, only $3(13 \%)$ lost enough weight to attain a $\mathrm{BMI}<35 \mathrm{~kg} / \mathrm{m}^{2}$ and then undergo donation. No long-term outcomes were reported and it is uncertain whether these patients regained significant weight in the postoperative period.

Only 2 case reports with a total of 3 patients have reported outcomes of living kidney donation after predonation bariatric surgery. First, Branco et al reported a $>30 \%$ decrease in overall $\mathrm{BMI}$ and uneventful postoperative courses in 2 patients who underwent bariatric surgery in Brazil. ${ }^{19}$ Second, Koshy et al documented a percentage excess BMI decrease of $54 \%$ (BMI 41.5 to $32.6 \mathrm{~kg} / \mathrm{m}^{2}$ ) in a patient who underwent laparoscopic gastric banding in Australia. Eight months after an uncomplicated donation, the patient's followup BMI was relatively stable at $33.5 \mathrm{~kg} / \mathrm{m}^{2}$. Neither study includes long-term follow-up outcomes for their patients. Therefore, to understand what impact bariatric surgery might have among potential LKDs with obesity, its impact on the general population must be discussed.

\section{3 | WHAT ARE THE RISKS AND BENEFITS OF BARIATRIC SURGERY?}

Bariatric surgery is the most successful and longest-lasting treatment for morbid obesity. Current National Institutes of Health (NIH) and Centers for Medicare \& Medicaid Services (CMS) guidelines for bariatric surgery require the patient to have either (1) BMI $\geq 40 \mathrm{~kg} / \mathrm{m}^{2}$ or (2) BMI $35-40 \mathrm{~kg} / \mathrm{m}^{2}$ with $\geq 1$ obesity-related comorbidity (eg, diabetes, hypertension, dyslipidemia, heart disease, obstructive sleep apnea, and so on), and have been previously unsuccessful with medical treatment for obesity. ${ }^{20,21}$ Approximately 216000 bariatric surgeries were performed in the United States in 2016. ${ }^{22}$ These include the Roux-en-Y gastric bypass (RYGB), laparoscopic sleeve gastrectomy (LSG), and

TA B LE 1 Summary table of donor outcomes after obese living kidney donation, recipient outcomes after obese living kidney donation, and outcomes after bariatric surgery in the general population

\begin{tabular}{|c|c|c|}
\hline $\begin{array}{l}\text { Donor outcomes after obese living } \\
\text { kidney donation }\end{array}$ & $\begin{array}{l}\text { Recipient outcomes after obese living } \\
\text { kidney donation }\end{array}$ & Bariatric surgery outcomes in general population \\
\hline $\begin{array}{l}\text { - Higher long-term risk of developing } \\
\text { ESRD that is dose-dependent per } \\
\text { unit BMI above } 27 \mathrm{~kg} / \mathrm{m}^{2} \\
\text { - Higher post-donation rates of de } \\
\text { novo diabetes, hypertension, and } \\
\text { dyslipidemia } \\
\text { - More likely to experience } \\
\text { short-term postdonation decline in } \\
\text { eGFR } \\
\text { - More likely to experience further } \\
\text { weight gain }\end{array}$ & $\begin{array}{l}\text { - Increased risk of graft loss that is } \\
\text { dose-dependent ( } 12 \% \text { increased risk per } \\
10 \text {-unit increase in donor BMI) } \\
\text { - Increased risk of mortality for recipients } \\
\text { of kidneys whose living donors subse- } \\
\text { quently developed ESRD }\end{array}$ & $\begin{array}{l}\text { - One-year excess BMI decrease of } 49 \%-72 \% \text { that is } \\
\text { sustained at } 5 \text {-years } \\
\text { - Comorbidity remission rates: } \\
\text { Diabetes }=12 \%-62 \% \\
\text { Hypertension }=29 \%-63 \% \\
\text { Dyslipidemia }=43 \%-47 \% \\
\text { Hyperuricemia }=100 \% \\
\text { - Long-term rates of reoperation: } \\
\text { Hernia ( } 2 \%-8 \%) \\
\text { GERD }(5 \%-10 \%) \\
\text { - De novo comorbidity rates: } \\
\text { Diabetes }=0.0 \%-0.2 \% \\
\text { Hypertension }=1.0 \%-5.4 \% \\
\text { Dyslipidemia }=2.8 \%-9.1 \% \\
\text { Hyperuricemia }=0.0 \%\end{array}$ \\
\hline
\end{tabular}


250,000

FIGURE 1 Metabolic and bariatric surgery procedure trend, 2011-2016. ${ }^{22}$ RYGB, Roux-en-Y gastric bypass; BPD/DS, biliopancreatic diversion with duodenal switch [Color figure can be viewed at wileyonlinelibrary.com]

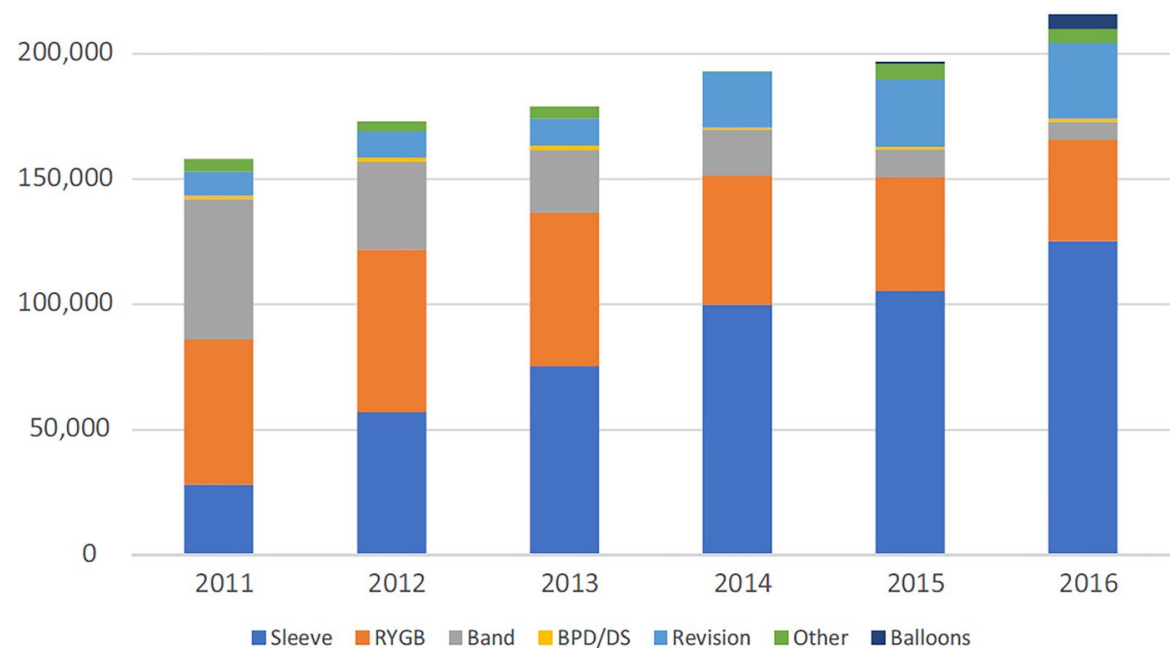

revision surgery (ie, LSG to RYGB). The most common operation today is LSG, accounting for $70 \%$ of primary bariatric operative procedures [Figure 1]. Given the association of RYGB with oxalate nephropathy, we maintain that barring contraindication, LSG should be the recommended procedure for morbidly obese potential LKDs and will focus on the risks and benefits of LSG for this section (Table 1).

Four recent clinical trials have shown excellent short- and longterm outcomes for LSG. First, the Swiss Multicentre Bypass or Sleeve Study (SM-BOSS) enrolled 217 patients from 4 Swiss centers comparing LSG to RYGB. ${ }^{23,24}$ Of the LSG patients ( $n=101$ ), percentage excess BMI loss at 1 year $=72.4 \%$ and 5 years $=61.1 \%$ (Figure 2 ). At 5 years, many LSG patients showed complete remission in diabetes ( $n=16 / 26,61.5 \%$ ), hypertension ( $n=40 / 64,62.5 \%$ ), dyslipidemia ( $n=29 / 68,42.6 \%$ ), and hyperuricemia ( $n=15 / 15,100 \%)$. Second, the Sleeve vs Bypass (SLEEVEPASS) randomized clinical equivalence trial recruited 240 patients from Finish centers comparing LSG to RYGB. ${ }^{25,26}$ Similar to the SM-BOSS trial, LSG patients $(n=121)$ experienced durable weight loss (\% excess BMI loss at 1 year = $57.8 \%$ and 5 years $=48.4 \%$ ), and complete remissions in diabetes ( $n=5 / 41,12.2 \%)$, hypertension $(n=20 / 68,29.4 \%$ ), and dyslipidemia ( $n=14 / 30,46.7 \%$ ). Third, the Surgical Therapy And Medications Potentially Eradicate Diabetes Efficiently (STAMPEDE) randomized control trial at the Cleveland Clinic recruited 150 patients with type 2 diabetes to undergo medical therapy, RYGB, or LSG. ${ }^{27-29}$ Of the LSG patients $(n=47)$, percentage excess BMI loss at 1 year $=82.7 \%$ and 5 years $=60.9 \%$, with complete diabetes remission in $23.4 \%$ ( $n=11 / 47$ ) of patients. Finally, Reges et al performed a retrospective cohort study comparing bariatric surgery with nonsurgical obesity management in a large Israeli integrated health care fund covering $54 \%$ of all Israeli citizens with $96.8 \%$ follow-up. ${ }^{30}$ After a median follow-up of 4.5 years, the LSG subgroup $(n=3362)$ had a median $\%$ excess $\mathrm{BMI}$ decrease of $69.0 \%$, with $70.8 \%$ of patients experiencing $a \geq 20 \%$ decrease in overall BMI.

Overall, the risks of major complications after LSG are low. The Metabolic and Bariatric Surgery Accreditation and Quality
Improvement Program (MBSAQIP) captures 30-day outcomes for $>98 \%$ of bariatric operations performed in the United States. According to unpublished 2015-2016 MBSAQIP data ( $N=212,543$ LSG operations), the 30-day mortality rate after LSG is $<0.1 \%$ and Clavien-Dindo III+IV complication rate is $2.1 \%$. The published long-term complications after LSG include hernia requiring reoperation ( $2 \%$ to $8 \%$ ) and the development or worsening of gastroesophageal reflux disease (GERD) in up to two-thirds of LSG patients that occasionally requires revision to RYGB $(5 \%$ to $10 \%$ of all LSG operations). ${ }^{23,25,29,30}$ Finally, de novo development of obesity-related comorbidities after LSG is infrequent: diabetes $=0.0 \%$ to $0.2 \%$, hypertension $=1 \%$ to $5 \%$, and dyslipidemia $=2 \%$ to $9 \% .^{23,30}$

\section{4 | WHAT ARE BARRIERS TO BARIATRIC SURGERY IN POTENTIAL LKDS WITH OBESITY?}

Given the long-term benefits and low-risk profile of bariatric surgery in the general population, its application to potential LKDs with morbid obesity seems self-evident. However, there are aspects of care unique to potential LKDs that make this less straightforward. These barriers center on 4 main areas: (1) ethically broaching the topic of obesity and weight-loss clinic referral in the transplant clinic setting; (2) payment source for weight-loss interventions; (3) subsequent decision for donor candidacy and timing of donation after bariatric surgery; and (4) paucity of outcomes data for donation after bariatric surgery.

Ethically broaching the topic of obesity and weight loss clinic referral with potential LKDs in the transplant clinic will be a complex and nuanced topic. Potential LKDs are the most benevolent patients that transplant surgeons encounter-they are willing to donate an organ to help another person. However, this makes them a vulnerable population, where family pressures and feelings of guilt may 
A Laparoscopic sleeve gastrectomy

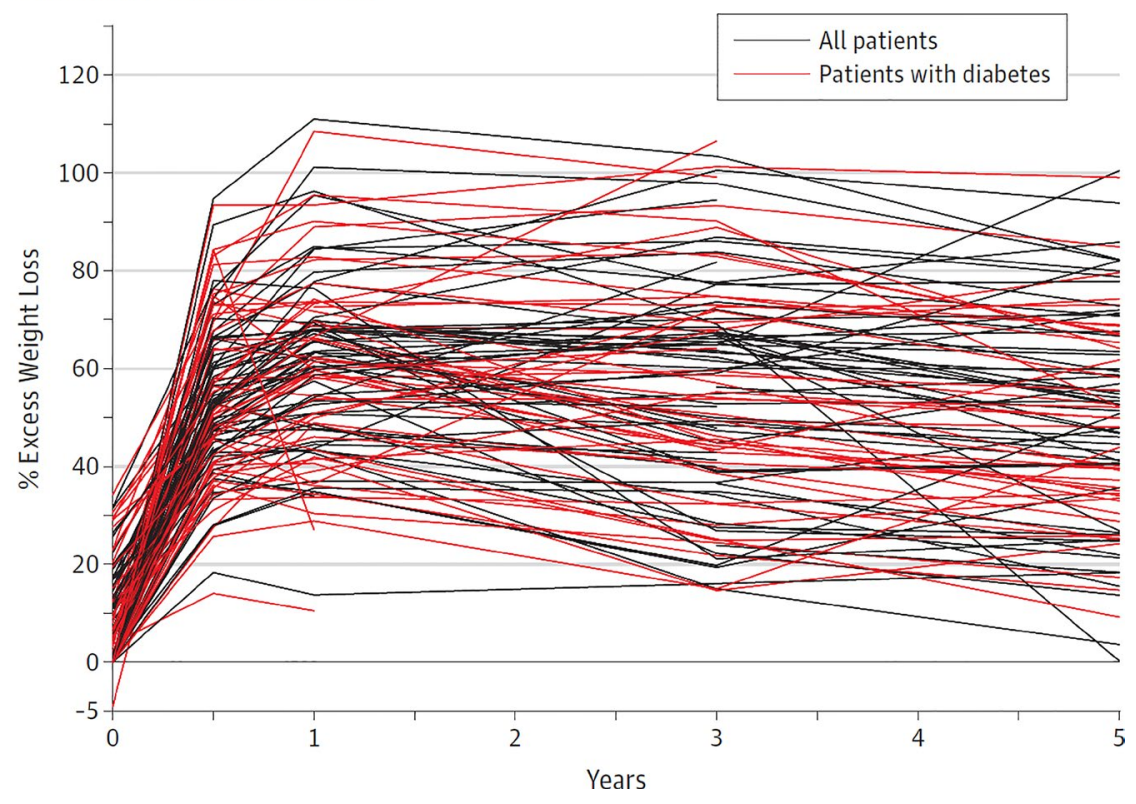

B Sleeve gastrectomy

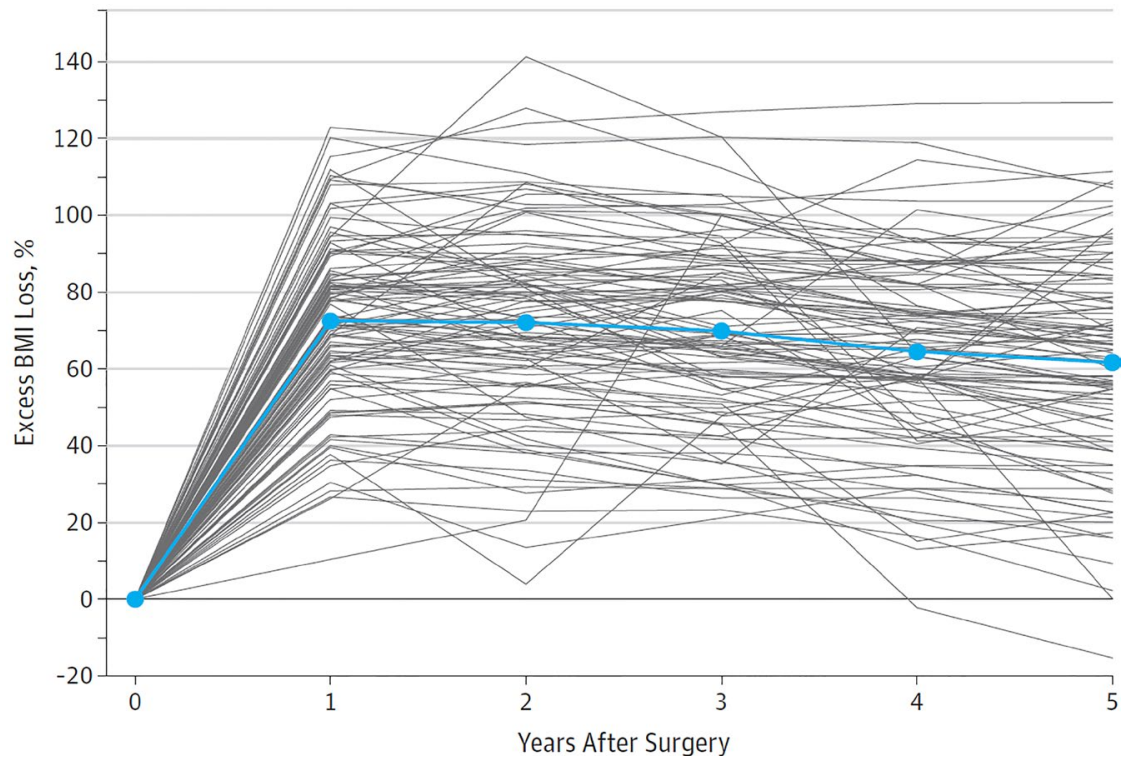

FIGURE 2 Percentage excess weight loss over 5-year follow-up for individual patients after laparoscopic sleeve gastrectomy from the (A) SLEEVEPASS and (B) SM-BOSS randomized clinical trials [Color figure can be viewed at wileyonlinelibrary.com] compromise their individual autonomy. Reese et al recently showed that feelings of disappointment, distress, and loss of life purpose are not uncommon among potential LKDs who are turned down for donation. ${ }^{31}$ Unless these factors are acknowledged, inadvertent coercion is possible.

During the discussion in the transplant clinic, 3 central steps must be taken. First, potential LKDs with obesity should be informed of the reason(s) that they are denied donation. This disclosure should be compassionate yet honest. Second, referral to an independent, comprehensive weight-loss and bariatric surgery clinic should be offered. This will be a difficult part of the conversation-certain patients will be caught off guard, some might feel resentful, and others might even see it as coercive (eg, "transplant surgeons want to put me through bariatric surgery just so they can remove my kidney").
During the discussion for referral, it must be made clear that the decision for any weight-loss intervention is predicated on the potential LKD's benefit alone, irrespective of possible future benefit to the intended recipient. As such, referral to an independent clinic for an unbiased discussion of the risks and benefits of weight-loss options is obligatory. Even if the potential LKD does not meet NIH/CMS criteria for bariatric surgery (ie, BMI $30-35 \mathrm{~kg} / \mathrm{m}^{2}$ ), referral to an independent clinic is useful for facilitation of other weight-loss interventions (ie, medications, diet/exercise) and to establish longitudinal follow-up. Finally, it must be made absolutely clear that successful weight loss may not result in ultimate donation to the intended recipient; other living or deceased donors might present before the potential LKD is eligible for donation, so ultimate donation cannot be promised. 
Second, payment for weight-loss clinic referral or bariatric surgery might become controversial. Normally, all expenses related to donation and subsequent care are paid in-full by the recipient's insurance. However, this arrangement is improper for obesity-related expenses among potential LKDs. Because the decisions for weightloss clinic referral and interventions are based on the potential LKD's health alone, payment by the intended recipient's insurance would be unethical and potentially coercive. Even so, one caveat exists. As described by Issa et al, LKDs who are initially obese but lose sufficient weight by diet and exercise in the predonation period to then undergo donation are more likely to regain it afterward and consequently have increased risk of developing future hypertension (relative risk [RR] 1.93, 95\% Cl 1.51-2.46) and diabetes (RR 4.18, 95\% Cl 2.05-8.50). ${ }^{32}$ For these patients, we suggest that payment by the recipient's insurance for weight-loss clinic referral and/or bariatric surgery is appropriate, as their previous donation puts them at higher risk of adverse outcomes from obesity. One critical area of future research related to this will be defining BMI cutoffs for bariatric surgery in patients who have already undergone donation. We propose that previous donation should be akin to an "obesity-related comorbidity" and allow previous LKDs to undergo bariatric surgery at a BMI $\geq 35 \mathrm{~kg} / \mathrm{m}^{2}$ cutoff, even without other obesity-related comorbidities such as hypertension or diabetes. However, this requires further study.

Third, determination of donor candidacy after bariatric surgery and timing of subsequent donation must be established. Given that sufficient weight loss is not guaranteed by any intervention and development of de novo obesity-related comorbidities is rare but possible, we discourage donation until potential LKDs meet prespecified transplant center donation eligibility requirements (ie, BMI $<30 \mathrm{~kg} / \mathrm{m}^{2}$ with nonprohibitive comorbidities) and have been stable with these characteristics for $\geq 3$ months. The first requirement is essential because potential LKDs should not be allowed to donate if they do not meet prespecified standards beforehand. The second requirement of stable eligibility for $\geq 3$ months before donation must be prospectively validated. One additional question for donor candidacy after bariatric surgery is whether age should influence this decision. Little is known about maintenance of weight loss beyond 5 years following bariatric surgery, and it is possible that compared to older patients, younger patients have a greater chance of regaining weight and/or comorbid conditions over a longer lifetime. Currently, there is insufficient evidence to recommend an "age minimum" for donation after bariatric surgery, but transplant surgeons must keep this possible long-term risk in mind when counseling younger potential LKDs on donation.

Finally, donor and recipient outcomes following donation after bariatric surgery are unknown. Existing evidence can be extrapolated to suggest that donation after bariatric surgery would have acceptable donor outcomes, but there have been no studies examining this. Furthermore, it is uncertain whether sufficient donor weight loss preoperatively will mitigate the known increased risk of recipient graft loss from obese donors. We propose that retrospective outcomes analyses of LKDs with a remote history of bariatric surgery would be the first step to bridge these knowledge gaps.

\section{5 | CONCLUSION}

The growing influx of obese LKD candidates will force transplant centers to design innovative solutions to optimally manage these patients. Donation with obesity portends real risks to living donors, and early referral to an independent, comprehensive weight-loss and bariatric surgery clinic may offer a unique and evidence-supported opportunity to improve the health of prospective LKDs with obesity. Transplant surgeons must become comfortable with facilitating these referrals for all potential LKDs with $\mathrm{BMI} \geq 30 \mathrm{~kg} / \mathrm{m}^{2}$. Ultimate weight-loss management decisions should be consistent with existing $\mathrm{NIH} / \mathrm{CMS}$ guidelines and made between the patient and an independent physician. Future research is needed to determine the appropriate donor candidacy after weight-loss interventions, optimal timing of donation following bariatric surgery, and suitable BMI cutoff for bariatric surgery among previous LKDs who go on to develop obesity.

\section{DISCLOSURE}

The authors of this manuscript have no conflicts of interest to disclose as described by the American Journal of Transplantation.

ORCID

John R. Montgomery (iD https://orcid.org/0000-0001-7751-231X

\section{REFERENCES}

1. NCHS, National Health and Nutrition Examination Survey. 2017. https://www.cdc.gov/nchs/data/hus/2017/058.pdf Accessed November 5, 2018.

2. Sachdeva M, Rosen LM, Varghese J, Fishbane S, Molmenti EP. Weight trends in United States living kidney donors: analysis of the UNOS database. World J Transplant. 2015;5(3):137-144.

3. UNOS Standard Transplant Analysis and Research Files, H.R.a.S.A. U.S. Department of Health and Human Services, Editor. 2018. https://optn.transplant.hrsa.gov/data/request-data/. Accessed June 8, 2018.

4. Lapasia JB, Kong SY, Busque S, Scandling JD, Chertow GM, Tan JC. Living donor evaluation and exclusion: the Stanford experience. Clin Transplant. 2011;25(5):697-704.

5. Sachdeva M, Sunday S, Israel E, et al. Obesity as a barrier to living kidney donation: a center-based analysis. Clin Transplant. 2013;27(6):882-887

6. Norman SP, Song PX, Hu Y, Ojo AO. Transition from donor candidates to live kidney donors: the impact of race and undiagnosed medical disease states. Clin Transplant. 2011;25(1):136-145.

7. Kumar K, Tonascia JM, Muzaale AD, et al. Racial differences in completion of the living kidney donor evaluation process. Clin Transplant. 2018:32(7):e13291.

8. Weng FL, Dhillon N, Lin Y, Mulgaonkar S, Patel AM. Racial differences in outcomes of the evaluation of potential live kidney donors: a retrospective cohort study. Am J Nephrol. 2012;35(5):409-415.

9. Lunsford SL, Simpson KS, Chavin KD, et al. Racial disparities in living kidney donation: is there a lack of willing donors or an 
excess of medically unsuitable candidates? Transplantation. 2006;82(7):876-881.

10. Reeves-Daniel A, Adams PL, Daniel K, et al. Impact of race and gender on live kidney donation. Clin Transplant. 2009;23(1):39-46.

11. Locke JE, Reed RD, Massie A, et al. Obesity increases the risk of end-stage renal disease among living kidney donors. Kidney Int. 2017;91(3):699-703.

12. Unger LW, Feka J, Sabler P, et al. High BMI and male sex as risk factor for increased short-term renal impairment in living kidney donors - Retrospective analysis of 289 consecutive cases. Int J Surg. 2017;46:172-177.

13. Holscher CM, Ishaque T, Garonzik Wang JM, et al. Living donor post-nephrectomy kidney function and recipient graft loss: a doseresponse relationship. Am J Transplant. 2018;18(11):2804-2810.

14. Movassaghi M, Dru C, Koopman S, Fuchs GJ. Trends in body-mass index after donor nephrectomy [published online ahead of print 2014]. J Endourol. https://doi.org/10.1089/end.2013-0196.ecc13

15. Nogueira JM, Weir MR, Jacobs S, et al. A study of renal outcomes in obese living kidney donors. Transplantation. 2010;90(9):993-999.

16. Tavakol MM, Vincenti FG, Assadi H, et al. Long-term renal function and cardiovascular disease risk in obese kidney donors. Clin J Am Soc Nephrol. 2009;4(7):1230-1238.

17. Massie AB, Leanza J, Fahmy LM, et al. A risk index for living donor kidney transplantation. Am J Transplant. 2016;16(7):2077-2084.

18. Muzaale AD, Massie AB, Anjum S, et al. Recipient outcomes following transplantation of allografts from live kidney donors who subsequently developed end-stage renal disease. Am J Transplant. 2016;16(12):3532-3539.

19. Branco AW, Branco Filho AJ, Kondo W. Laparoscopic live donor nephrectomy in patients surgically treated for morbid obesity. Int Braz J Urol. 2007;33(3):377-379; discussion 379.

20. Clinical Guidelines on the Identification Evaluation, and treatment of overweight and obesity in adults-the evidence report. National Institutes of Health. Obes Res. 1998;6(Suppl 2):51s-209s.

21. Centers for Medicare \& Medicaid Services: Medicare national coverage determinations manual. https://www.cms.gov/manuals/ downloads/ncd103c1_Part2.pdf. Accessed November 6, 2018.

22. English WJ, DeMaria EJ, Brethauer SA, Mattar SG, Rosenthal RJ, Morton JM. American Society for Metabolic and Bariatric Surgery estimation of metabolic and bariatric procedures performed in the United States in 2016. Surg Obes Relat Dis. 2018;14(3):259-263.

23. Peterli R, Wölnerhanssen BK, Peters T, et al. Effect of laparoscopic sleeve gastrectomy vs laparoscopic Roux-en-Y gastric bypass on weight loss in patients with morbid obesity: the SM-BOSS randomized clinical trial. JAMA. 2018;319(3):255-265.

24. Peterli R, Wölnerhanssen BK, Vetter D, et al. Laparoscopic sleeve gastrectomy versus Roux-Y-Gastric bypass for morbid obesity-3year outcomes of the prospective randomized Swiss Multicenter Bypass Or Sleeve Study (SM-BOSS). Ann Surg. 2017;265(3):466-473.

25. Salminen P, Helmiö M, Ovaska J, et al. Effect of laparoscopic sleeve gastrectomy vs laparoscopic Roux-en-Y gastric bypass on weight loss at 5 years among patients with morbid obesity: the SLEEVEPASS randomized clinical trial. JAMA. 2018;319(3):241-254.

26. Helmiö M, Victorzon M, Ovaska J, et al. Comparison of short-term outcome of laparoscopic sleeve gastrectomy and gastric bypass in the treatment of morbid obesity: a prospective randomized controlled multicenter SLEEVEPASS study with 6-month follow-up. Scand J Surg. 2014;103(3):175-181.

27. Schauer PR, Kashyap SR, Wolski K, et al. Bariatric surgery versus intensive medical therapy in obese patients with diabetes. $N$ Engl J Med. 2012;366(17):1567-1576.

28. Schauer PR, Bhatt DL, Kirwan JP, et al. Bariatric surgery versus intensive medical therapy for diabetes-3-year outcomes. N Engl J Med. 2014;370(21):2002-2013.

29. Schauer PR, Bhatt DL, Kirwan JP, et al. Bariatric surgery versus intensive medical therapy for diabetes - 5-year outcomes. N Engl J Med. 2017;376(7):641-651.

30. Reges O, Greenland P, Dicker D, et al. Association of bariatric surgery using laparoscopic banding, Roux-en-Y gastric bypass, or laparoscopic sleeve gastrectomy vs usual care obesity management with all-cause mortality. JAMA. 2018;319(3):279-290.

31. Reese PP, Allen MB, Carney C, et al. Outcomes for individuals turned down for living kidney donation. Clin Transplant. 2018;32:e13408.

32. Issa N, Sánchez OA, Kukla A, et al. Weight gain after kidney donation: association with increased risks of type 2 diabetes and hypertension. Clin Transplant. 2018;32:e13360.

How to cite this article: Montgomery JR, Telem DA, Waits SA.

Bariatric surgery for prospective living kidney donors with obesity? Am J Transplant. 2019;19:2415-2420. https://doi. org/10.1111/ajt.15260 